\title{
Transmission line fault distance and direction estimation using artificial neural network
}

\author{
Anamika Yadav ${ }^{1}$, A.S. Thoke ${ }^{2}$ \\ ${ }^{12}$ Department of Electrical Engineering, National Institute of Technology Raipur, INDIA \\ ${ }^{1 *}$ Corresponding Author: e-mail: anamikajugnu4@gmail.com,Tel +91-9425852654
}

\begin{abstract}
An accurate fault distance and direction estimation based on application of artificial neural networks for protection of doubly fed transmission lines is presented in this paper. The proposed method uses the voltage and current available at only the local end of line. This method is adaptive to the variation of fault location, fault inception angle and fault resistance. The Simulation results show that single phase-to-ground faults (both forward and reverse) can be correctly detected and located after one cycle after the inception of fault. Large number of fault simulations using MATLAB ${ }^{\circledR}$ has proved the accuracy and effectiveness of the proposed algorithm. The proposed scheme has significant advantage over more traditional direction relaying algorithms viz. it is suitable for high resistance fault. It has the operating time of less than 1.5 cycles. The proposed scheme allows the protection engineers to increase the reach setting upto $90 \%$ of the line length i.e. greater portion of line length can be protected as compared to earlier techniques in which the reach setting is $80-85 \%$ only.
\end{abstract}

Keywords: Artificial neural network, transmission line protection, fault detection, fault direction estimation and distance location.

DOI: http://dx.doi.org/10.4314/ijest.v3i8.9

\section{Introduction}

Transmission lines are subjected to many kinds of faults. Accurate and fast fault detection; direction estimation and distance location under a variety of fault conditions is important requirements from the point of service restoration and reliability. The methods of fault detection, direction estimation and fault distance location can be classified into the following three categories: power frequency components-based methods, transient signals-based methods and superimposed components-based methods. Directional relays based on negative or zero sequence components or compensated post fault voltages are most common (He et al. 1984 and Xia et al., 1992). These relays have inherent drawback of their inability to respond to all types of faults and slow operating time. To reduce the operating time, directional relays based on travelling waves have been proposed in (Johns, 1980; Johns. et al. 1986; Lyonette et. al., 2000). Directional comparison protection scheme based on superimposed component has been developed in Crossley et al. (1989). Further estimation of accurate fault location can reduce the fault clearing time. But fault location depends upon fault resistance and remote end in-feed etc, which may result in poor discrimination between the faulty and healthy line especially in the case of faults near the remote end bus.

In Sidhu et al. (1995), the direction of the fault on a transmission line has been determined by the ANN based network from the relative phase angles of instantaneous voltages and current phasors. However it does not determines the fault location. A directional relaying algorithm based on relative phase angles between positive-sequence fault components of voltages and currents has been developed for all types of faults (Gao et al., 2006). It does not identify the faulty phase and the distance to fault point. There are many papers which uses artificial intelligent methods in particular artificial neural network for fault classification, faulted-phase selection and fault distance location (Kezunoic, 1997; Oonsivilai et al., 2009, Kamel et al., 2010, Jain et al. 2006; Coury et al., 1998; Khaparde et al., 1996; Chunju et al., 2007; Mazon et al., 2000; Reddy et al., 2006 and 2007; Sanaye-Pasand et al., 2006). However the system considered in these papers is one section line which does not deals with fault direction estimation 
(Forward or reverse). Application of support vector machines for fault diagnosis in power transmission system has been reported recently (Ravikumar et al., 2008; Salat and Osowski, 2004; Samantaray et al., 2007, 2008). A decision tree-based fault zone identification and fault classification in flexible AC transmission-based transmission line has been reported which is based on data mining classification algorithm (Samantaray, 2009). Fault classification and faulty section identification in teed transmission circuits containing three sources has been reported using ANN (Warlyani et. al. 2011). A survey of the developments in digital relays for protection of transmission lines has been reported by Venkataramana et al. (2011).

This paper presents an application of artificial neural network for fault direction estimation alongwith fault location in a double end fed single circuit transmission line using only one terminal data. The effects of varying fault location, fault inception angle, fault resistance and remote source infeed have been considered in this work. The algorithm employs the fundamental components of three phase voltages and currents measured at one end only. The performance of the proposed scheme has been investigated by a number of offline tests. The Simulation results show that phase-to-ground can be correctly detected as forward or reverse fault and also it determines the fault location after one cycle from the inception of fault.

\section{Power system under study}

For the analysis of operation of the proposed ANN based relay, the power system shown in Fig. 1 is used. The power system is composed of two sections of $400 \mathrm{KV}$ single circuit transmission lines each of $100 \mathrm{~km}$ length. The grids at both ends of the line are modelled by Thevenin equivalents: a voltage source with it's short-circuit impedance represented by short circuit capacity of 1.2GVA and X/R ratio=8. Two ANN based relay FL-1 and FL-2 have been developed for fault detection, directional estimation and fault distance location. FL1 detects all type of shunt faults to be in forward direction and FL2 detects reverse fault when fault is in setion-1 and forward fault when fault is in section-2. Figure 2 shows the power system network model simulated in MATLAB ${ }^{\circledR} 7.01$ Simulink software. A load of $400 \mathrm{kV}, 50 \mathrm{MW}$ and $50 \mathrm{MVAR}$ rating is connected at the sending end bus1 through a separate transmission line of $100 \mathrm{~km}$. The receiving end bus3 is directly connected to load of $400 \mathrm{kv}, 100 \mathrm{MW}$ and $100 \mathrm{MVAR}$ rating. The fault breaker is used to generate the fault and to vary the fault inception angle and fault resistance. The lines are bifurcated into two segments to enable us to vary the fault location.

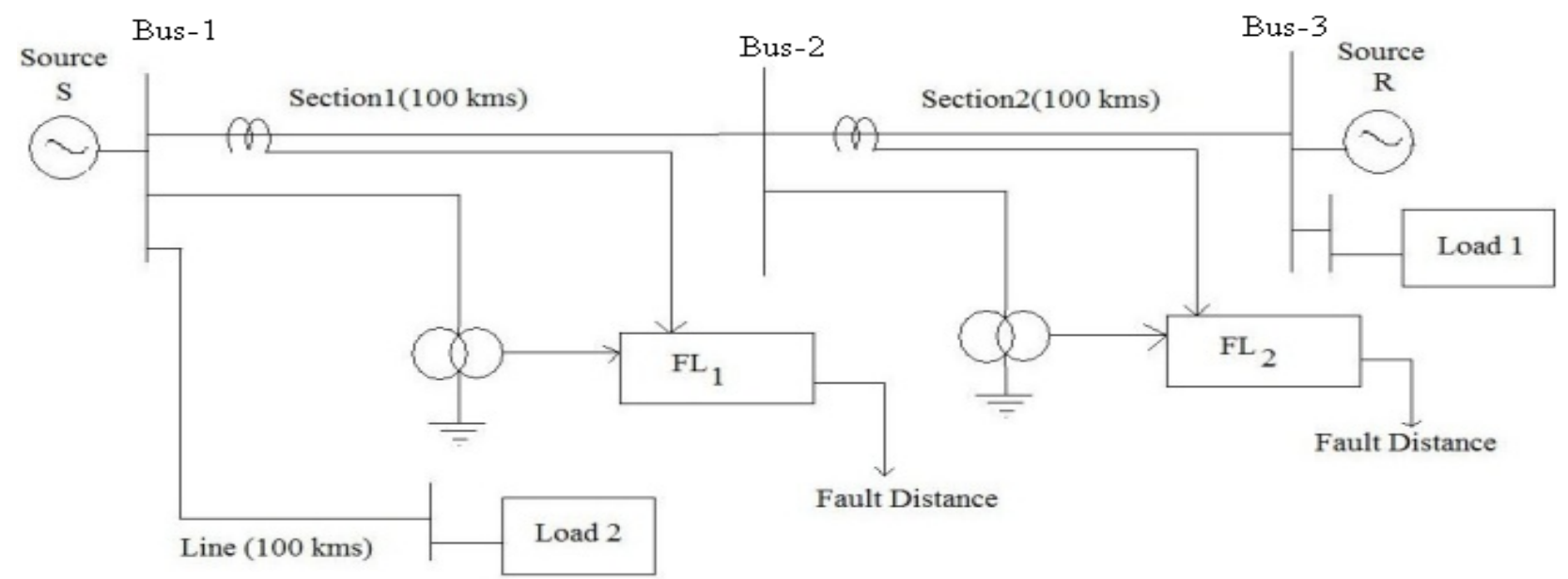

Figure 1. Single line diagram of Power System under Study

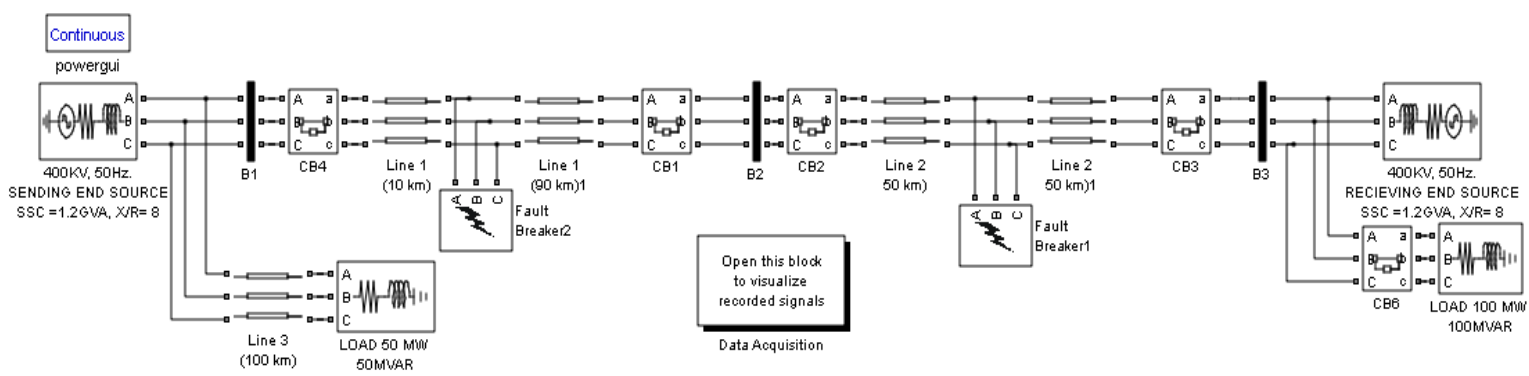

Figure 2. Power system model simulated in MATLAB Simulink software. 
Figure 3 shows the voltage and current waveforms during an 'AG'-phase to ground fault occurs at $70 \mathrm{KM}$ from sending end bus- 1 at $62.5 \mathrm{~ms}$ with zero fault resistance and $45^{\circ}$ fault inception angle. During fault period voltage decreases and current increases in the phase having the fault due to short circuit leaving the other two phases unaffected.

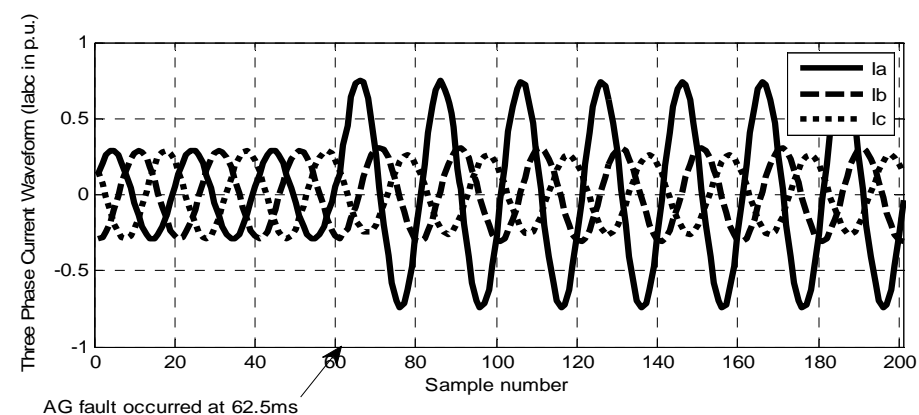

AG fault occurred at $62.5 \mathrm{~ms}$

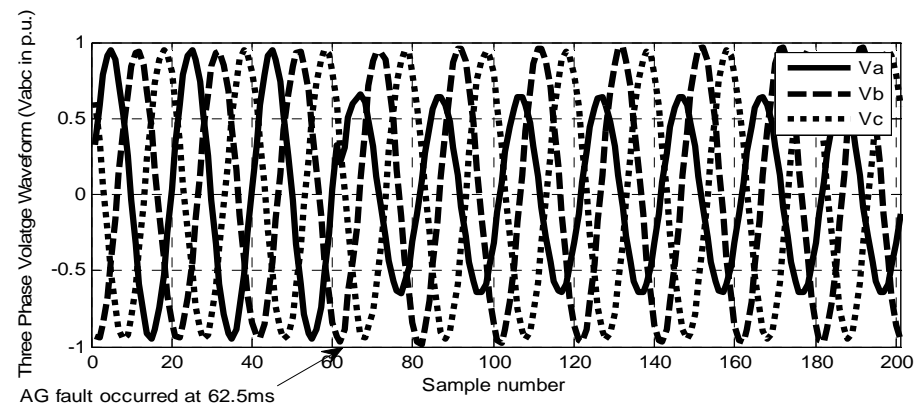

Figure 3. Three phase voltages and currents during phase A to ground fault at $70 \mathrm{~km}$ from sending end with fault resistance of $0 \Omega$ at fault inception time $62.5 \mathrm{~ms}$

2.1 Fault Patterns Generation Using MATLAB SIMULINK software: Data acquisition block depicted in power system model simulated in MATLAB Simulink software has been used to collect the three phase voltage and current signals measured at bus-1,2 and 3 as shown in Figure 2. A combination of different fault situations was considered and training patterns were generated by simulating using the fault breaker-1, 2. Different single line to ground faults have been simulated with varying fault locations, fault resistances and fault inception times (angles) to obtain a number of training patterns covering a wide range of different power system conditions.

2.2 Preprocessing of Voltage and Currents signal: Preprocessing of the three phase voltage and current signals measured at one end only can significantly reduces the size of the neural network and improves the performance and speed of training process. The training patterns pre-processing process is depicted in Figure 4 and discussed in detailed in the following sub-sections. Computer relays use the phasor representing the fundamental frequency of a waveform sampled over a finite window. A discrete fourier transform is the most common method to calculate the fundamental frequency components.

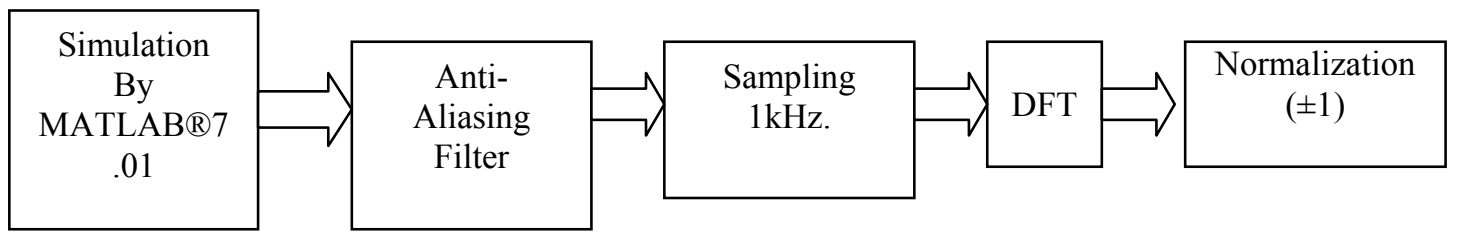

Figure 4. Training patterns generation and pre-processing process.

2.2.1 Anti-Aliasing Filter: The anti-aliasing filter removes the unwanted frequencies from a sampled waveform. If the nyquist frequency corresponds to a sampling rate of $\mathrm{N}$ times per cycle, it also determines the highest order harmonic frequency in the waveform which can be estimated. Of particular concern is the fundamental phasor, which is used in relay applications. The anti-aliasing filter removes harmonics above half the nyquist frequency to prevent corruption of the desired phasor. A simple 2nd-order low-pass Butter worth filter with cut-off frequency of $400 \mathrm{~Hz}$ has been used to filter the higher order harmonics.

2.2.2 Sampling Rate: Computer relays generally sample waveforms between 4 and 64 times per cycle. Reliable relaying decisions need to be made based upon at least 6 to 10 samples. A high sampling rate appears likely to produce a more accurate result. However, there must be enough time between samples to perform relay calculations. A sampling rate of 20 times per cycle 
seems to be a good compromise, and is very commonly used. Three phase voltages and three phase current signals were sampled at a sampling frequency of $1 \mathrm{KHz}$

2.2.3 Discrete Fourier Transform: Discrete Fourier Transform is used to convert sampled data into a representation of the fundamental frequency phasor. The Discrete Fourier Transform for the $\mathrm{p}^{\text {th }}$ harmonic phasor at a sampling rate of $\mathrm{N}$ times a cycle is given in equation

$$
V_{p}=\frac{2}{\sqrt{2} N} n \sum_{\substack{\sum V_{n} \\ n=0}}^{N-1} e^{-\frac{j 2 n p}{N}}
$$

2.2.4 Normalization: It should be mentioned that the input signals have to be normalized in order to reach the ANN input level $( \pm 1)$. The routine 'minmax' of the neural network toolbox of MATLAB ${ }^{\circledR}$ version 7.01 software is used to normalize the input signals. A moving data window of one cycle length is used to select the post fault data as input to the artificial neural network. Data strings of 10 consecutive samples of fundamental components of three phase voltage and current signals sampled at $1 \mathrm{KHz}$ are found to be appropriate inputs to the proposed neural network based Directional Fault Distance Locator. This represents a moving data window length of $10 \mathrm{~ms}$. Training matrices were built in such a way that the network trained produces an output corresponding to the distance to fault point including its direction (forward or reverse).

\section{Proposed ANN Based Directional Fault Distance Locator}

The ANN based fault distance estimation network is located at bus- 1 and also at bus- 2 . These two networks uses the voltage and current signals measured at respective buses. For bus- 1 the ANN based fault location estimation network is designated as FL-1 and for bus-2 as FL-2. The basic points of the procedure used to implement neural network in the fault location estimation algorithm are described in this section.

3.1 Selection of Inputs and Outputs of Neural Network: One factor in determining the right size and structure for the network is the number of inputs and outputs that it must have. The lower the number of inputs, the smaller the network can be. However, sufficient input data to characterize the problem must be ensured. The inputs to distance relay are mainly the voltages and currents, thus three phase voltage and current signals fundamental components have been used as input to ANN based relay.

The magnitudes of the fundamental components $(50 \mathrm{~Hz})$ of three consecutive post fault samples of each phase voltage and current measured at the relay location e.g. $\mathrm{V}_{\mathrm{a} 1}, \mathrm{~V}_{\mathrm{a} 2}, \mathrm{~V}_{\mathrm{a} 3}$ and $\mathrm{I}_{\mathrm{a} 1}, \mathrm{I}_{\mathrm{a} 2}$, and $\mathrm{I}_{\mathrm{a} 3}$ for " $\mathrm{A}$ " phase have been selected as input to neural network. This process is repeated for phases $\mathrm{B}$ and $\mathrm{C}$ also. Thus total $6 \times 3=18$ inputs are given to neural network for fault direction and distance estimation task. Thus the total no. of inputs $\mathbf{X}$ for the neural network are 18:

$$
\mathrm{X}=\left[\mathrm{V}_{\mathrm{a} 1}, \mathrm{~V}_{\mathrm{a} 2}, \mathrm{~V}_{\mathrm{a} 3}, \mathrm{~V}_{\mathrm{b} 1}, \mathrm{~V}_{\mathrm{b} 2}, \mathrm{~V}_{\mathrm{b} 3}, \mathrm{~V}_{\mathrm{c} 1}, \mathrm{~V}_{\mathrm{c} 2}, \mathrm{~V}_{\mathrm{c} 3}, \mathrm{I}_{\mathrm{a} 1}, \mathrm{I}_{\mathrm{a} 2}, \mathrm{I}_{\mathrm{a} 3}, \mathrm{I}_{\mathrm{b} 1}, \mathrm{I}_{\mathrm{b} 2}, \mathrm{I}_{\mathrm{b} 3}, \mathrm{I}_{\mathrm{c} 1}, \mathrm{I}_{\mathrm{c} 2}, \mathrm{I}_{\mathrm{c} 3}\right]
$$

Further the basic task of fault location estimation network is to determine the location of fault from the corresponding relay location; only one output corresponding to the distance of the fault from the corresponding relay is considered as the output provided by the network. The response of the network will be the numerical value of distance of the fault from the relay ( + ve value for forward fault and -ve value for reverse fault). Thus the output $\mathbf{Y}$ of the directional fault location estimation network is:

$$
\mathrm{Y}= \pm\left[\mathrm{L}_{\mathrm{f}}\right]
$$

Where $\mathrm{L}_{\mathrm{f}}$ is the fault distance estimated by the neural network from the relay location.

3.2 ANN Architecture: Once it was decided how many input and output the ANN should have, the number of layers and the number of neurons per layer and the training algorithm were considered. The various learning algorithms viz. batch gradient descent (traingd), batch gradient descent with momentum (traingdm), variable learning rate backpropagation (traingda), resilient backpropagation (trainrp) and levenberg-marquardt (trainlm) were applied to the different network architectures tested. It was concluded that the most suitable training method for the architecture selected was based on the Levenberg-Marquardt (LM) optimization technique. Various networks with different no. of neurons in the hidden layer of ANN Based Fault distance estimator (FL1 and FL-2) e.g. 4, 6...30 neurons and one neuron in the output layer were investigated. Comparisons of architectures of FL-1 and FL-2 with different no. of neuron in the hidden layer are shown in Table 1 and 2 respectively.

After experimenting on various networks with different no. of neurons in the hidden layer for fault distance location task as per Table- 1 and 2, single layer network with 18 inputs and 8 and 7 neurons in hidden layer for FL1 and FL2 respectively and 1 in the output layer were found to be suitable. The final determination of the neural network requires the relevant transfer functions to be established. After analyzing the various possible combinations of transfer functions usually used, such as logsig, tansig and linear functions, the function "tansig" in hidden layer and "purelin" in the output layer for both FL-1 and FL-2 have been used. 
Figures 5, 6 show the final architecture of ANN base fault locator for FL1 and FL2 respectively. In this case number of neurons in input and output layers are fixed 18 and 1 respectively. Numbers of neurons in hidden layer are 8 and 7 for FL1 and FL2 respectively.

Table 1. Comparison of architectures of FL-1

\begin{tabular}{|l|l|l|l|}
\hline $\begin{array}{l}\text { Number of neurons } \\
\text { in hidden layer }\end{array}$ & Mean square Error & $\begin{array}{l}\text { Number } \\
\text { Epochs }\end{array}$ & ANN architecture \\
\hline 2 & 0.0192 & 28 & $18-2-1$ \\
\hline 4 & 0.000254 & 152 & $18-4-1$ \\
\hline 6 & 0.000260 & 54 & $18-6-1$ \\
\hline 7 & 0.000192 & 164 & $18-7-1$ \\
\hline 8 & $9.99 \mathrm{e}-05$ & 109 & $18-8-1$ \\
\hline
\end{tabular}

Table 2. Comparison of architectures of FL-2

\begin{tabular}{|l|l|l|l|}
\hline $\begin{array}{l}\text { Number of neurons } \\
\text { in hidden layer }\end{array}$ & Mean square error & Number of epochs & ANN architecture \\
\hline 3 & 0.0376 & 132 & $18-3-1$ \\
\hline 5 & 0.00205 & 115 & $18-5-1$ \\
\hline 6 & 0.000196 & 141 & $18-6-1$ \\
\hline 7 & $9.55 \mathrm{e}-05$ & 38 & $18-7-1$ \\
\hline
\end{tabular}

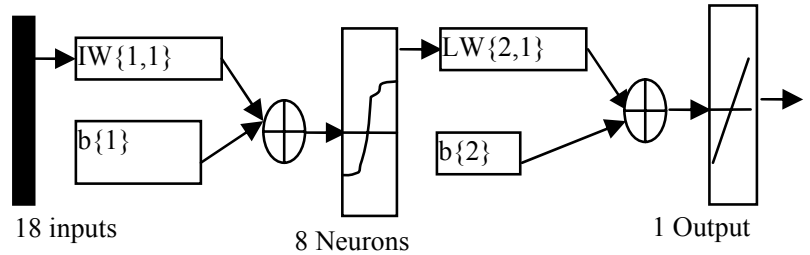

Figure 5. Final architecture of FL-1 ANN Based Fault locator.

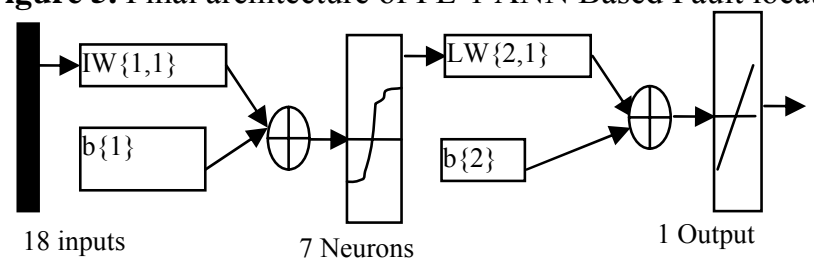

Figure 6. Final architecture of FL-2 ANN Based Fault locator.

3.3 Training Process: To train the network, a suitable number of representative examples of the relevant phenomenon must be selected so that the network can learn the fundamental characteristics of the problem and, once training is completed, provide correct outputs in new situations not envisaged during training. To obtain enough examples to train the network, a software package MATLAB ${ }^{\circledR} 7.10$ is used.

Each type of single line to ground fault at both sections (AG, BG, CG) at different fault locations between $0-100 \%$ of line length, fault resistance $(0,100 \Omega)$ and fault inception angles $\left(0 \& 90^{\circ}\right)$ have been simulated as shown below in Table 3 . The total number of fault simulated are 9 (locations) x2 (fault resistance) x3 (type of faults) x2 (fault inception angle) x2 (sections) $=216$. From each fault cases ten numbers of post fault samples has been extracted to form the total fault patterns 2160 and 20 samples of no fault situation are also added to form the training and testing data sets for neural network for the fault location estimation task. Thus the total number of patterns generated for training and testing are 2180 for the directional fault location estimation task.

Table-3. Patterns generation

\begin{tabular}{|l|l|}
\hline Parameter & Set value \\
\hline Fault type (Single line to ground faults) & $\begin{array}{l}\text { Section-1:AG, BG, CG } \\
\text { Section-2: AG, BG, CG }\end{array}$ \\
\hline Fault location Lf (km) in both the sections & $10,20,30, \ldots 80$ and $90 \mathrm{~km}$ \\
\hline Fault inception angle (Фi) ) in both the sections & $0 \& 90 \mathrm{deg}$ \\
\hline
\end{tabular}

The next step is to divide the total data into training, validation and test subsets. One fourth of the data (545) for the validation set, one fourth for the test set (545) and one half for the training set (1090) has been used. The data sets were picked as equally spaced points throughout the original data. Both the networks for fault direction estimation were trained using Levenberg- 
Marquardt training algorithm of neural network toolbox of MATLAB with the mean squared error set goal at 1e-04. This learning strategy converges quickly to the desired set goal. The mean squared error (mse) of FL-1 for training data set decreases in 109 epochs to 9.99e-05 as shown in Figure 7(a) by Blue line. Further the best validation data set performance curve is shown in green having "mse" of 0.0012951 in 109 epochs and red line for and test data set having "mse" less than that of validation data set for fault location estimation. The mean squared error (mse) of FL-2 for training data set decreases in 38 epochs to $9.55 \mathrm{e}-05$ as shown in Figure 7(b) by Blue line. Further the best validation data set performance curve is shown in green having mse of $8.9225 \mathrm{e}-005$ in 38 epochs and red line for and tests Data set having mse less than that of validation data set for fault location estimation.

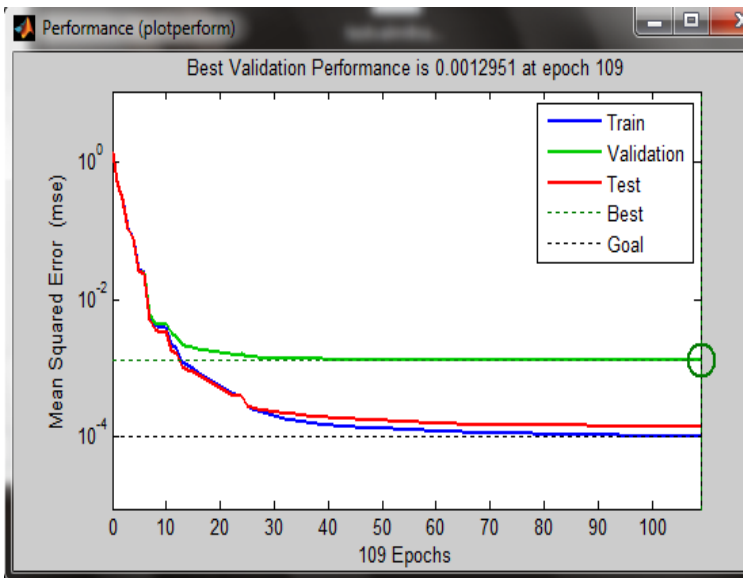

Figure 7(a)

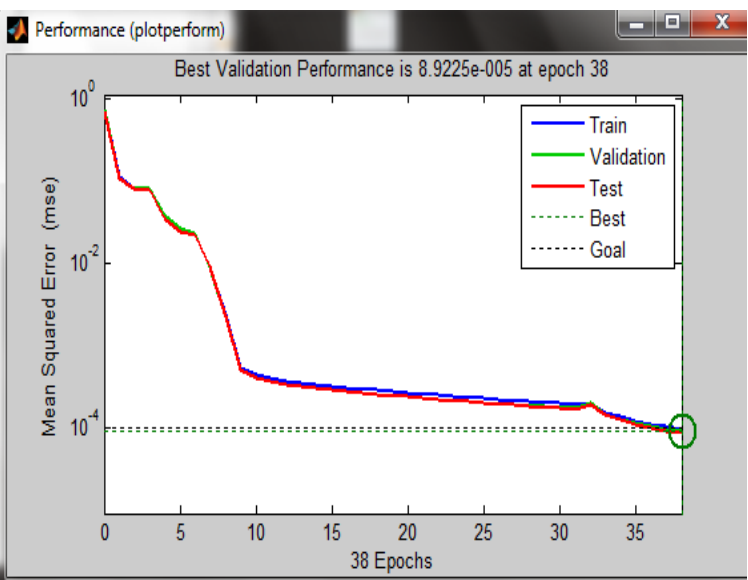

Figure 7(b)

Figure 7(a) and (b). Performance curve (mean squared error) of training, testing and validation data set for FL-1 and FL-2 respectively.

The Desired and Actual output of FL-1 obtained after training with the Levenberg-Marquardt training algorithm, fault location estimation network is shown in Figure 8. It can be seen that the fault location estimated by FL1 are all positive values showing forward fault, and the shape of graph both the graph is similar. During no fault situation i.e. between 545 to 550 sample number, the network is trained to show the output fault location as $210 \mathrm{~km}$.
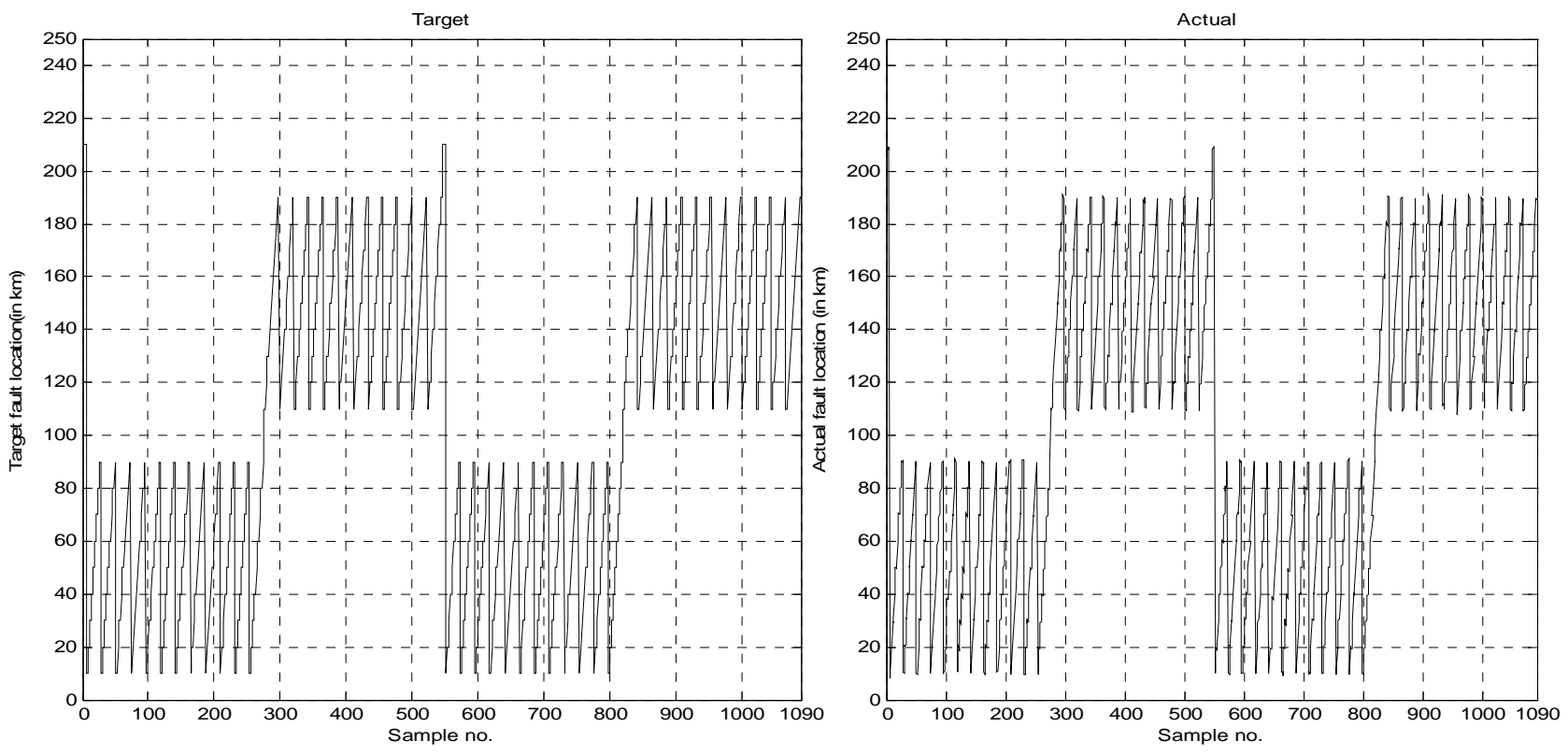

Figure 8. Comparison of target and actual outputs obtained after training of FL1.

(No fault values lying from sample no. 545 to 550).

\section{Simulation Results of ANN Based Fault Locator}


ANN based Fault locator was then extensively tested using data sets consisting of fault scenarios not used previously in training. For different faults of the validation/test data set, fault type, fault location and fault inception angle were changed to investigate the effects of these factors on the performance of the proposed algorithm. The network was tested and validated by presenting different phase to ground fault cases with varying fault locations $(\mathrm{Lf}=10-90 \mathrm{KM})$, fault resistance $(\mathrm{Rf}=0,100 \Omega)$ and fault inception angles $\left(\Phi \mathrm{i}=0-360^{\circ}\right)$. The results of the test of ANN based fault locator are shown in the following diagrams.

4.1 Test Results of Faults in Section-1: In Figure 9(a), Plot is obtained for output of FL-1 during BG fault at 25km from sending end with 0 (zero) $\Omega$ fault resistance and fault inception time $=0.0625 \mathrm{~s}$. The fault occurred at sample no. 21 with sampling time 1 ms and located at sample no. 30. There are 3 samples (consecutive sample) obtained by re-ordering of data in matrix.

Inception of fault at sample no. $21=21 * 3($ consecutive samples $) * 1 \mathrm{~ms}($ sampling time $)=63 \mathrm{~ms}$

Fault located at sample no. 30 as $26.0373 \mathrm{~km}=30 * 3$ (consecutive samples) $* 1$ (sampling time) $=90 \mathrm{~ms}$

Also, time of operation $=90-63=27 \mathrm{~ms}$ (more than one full cycle)

Time of operation in terms of cycles $=27 \mathrm{msec} / 20 \mathrm{~ms}=1.35$ cycle time.

In Figure 9(b), plot is obtained for output of FL-2 during BG fault at $25 \mathrm{~km}$ from sending end with $0 \Omega$ fault resistance and fault inception time $=0.0625 \mathrm{~s}$. The fault occurred at sample no. 21 and located at sample no. 29 as $-76.5693 \mathrm{~km}$. Negative value shows that the fault is in reverse direction from FL-2 and its distance from FL-2 is $76.5693 \mathrm{~km}$ and from FL-1 is 100-76.5693=23.4307 $\mathrm{km}$.

Inception of fault at sample no. $21=21 * 3($ consecutive samples $) * 1 \mathrm{~ms}($ sampling time $)=63 \mathrm{~ms}$

Fault located at sample no. $29=29 * 3$ (consecutive samples) $* 1$ (sampling time) $=87 \mathrm{~ms}$

Also, time of operation $=87-63=24 \mathrm{~ms}$ (more than one full cycle)

Time of operation in terms of cycles $=24 \mathrm{msec} / 20 \mathrm{~ms}=1.2$ cycle time

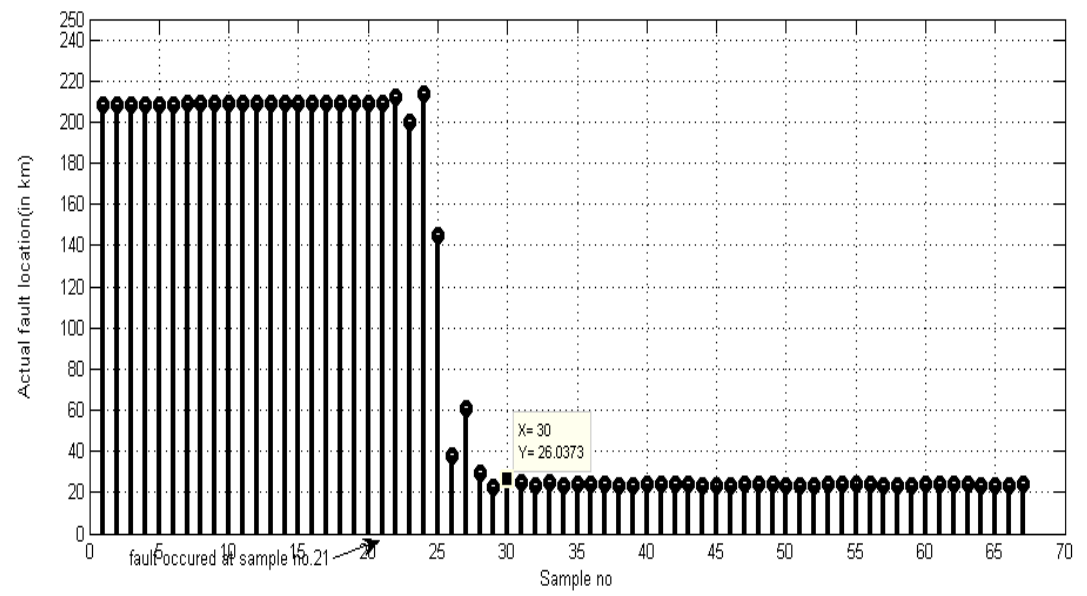

Figure 9(a). Test result of FL-1 during BG fault at $25 \mathrm{~km}$ from sending end with $0.001 \Omega$ fault resistance and fault inception time $=0.0625 \mathrm{~s}$. 


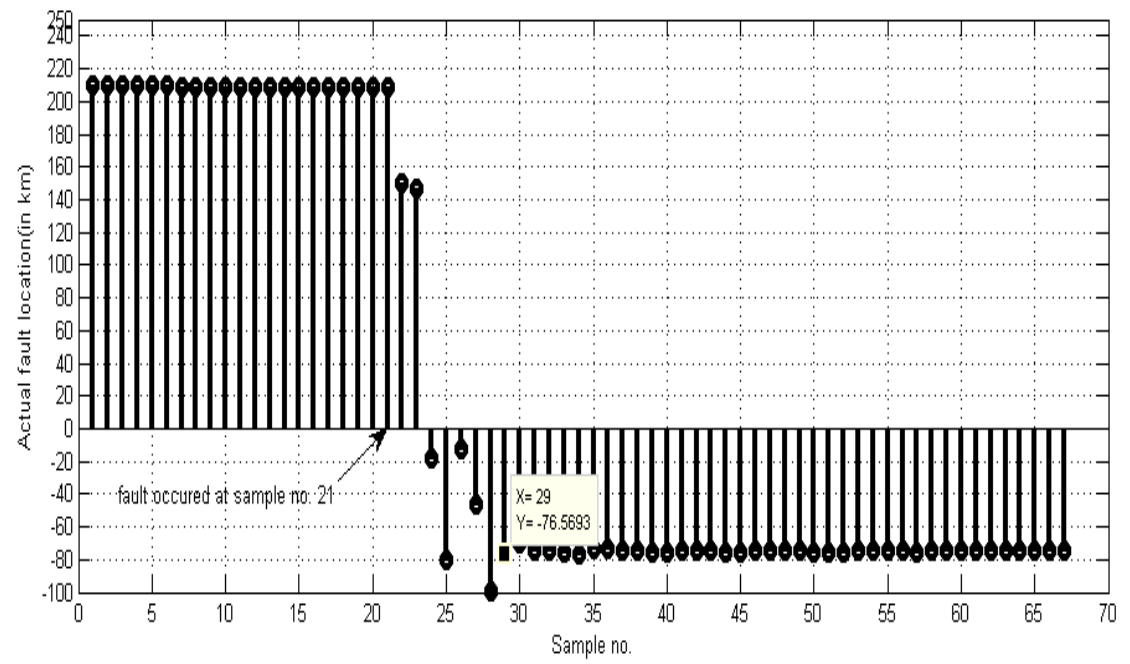

Figure 9(b). Test result of FL-2 during BG fault at $25 \mathrm{~km}$ from sending end with $0.001 \Omega$ fault resistance and fault inception time $=0.0625 \mathrm{~s}$.

4.2 Test Results of Faults in Section-2: In Figure 10(a), plot is obtained for output of FL-1 during AG fault at 190km from sending end with $100 \Omega$ fault resistance and fault inception time $=0.066 \mathrm{~s}$. The fault occurred at sample no. 22 and located at sample no. 31 as $190.0519 \mathrm{~km}$.

Inception of fault occurred at sample no. $22=22 * 3$ (consecutive samples) $* 1 \mathrm{~ms}($ sampling time) $=66 \mathrm{~ms}$ Fault located at sample no. $31=31 * 3$ (consecutive samples)*1(sampling time) $=93 \mathrm{~ms}$

Also time of operation $=93-66 \mathrm{~ms}=27 \mathrm{~ms}$ (more than one full cycle)

Time of operation in terms of cycles $=27 \mathrm{msec} / 20 \mathrm{~ms}=1.35$ cycle time

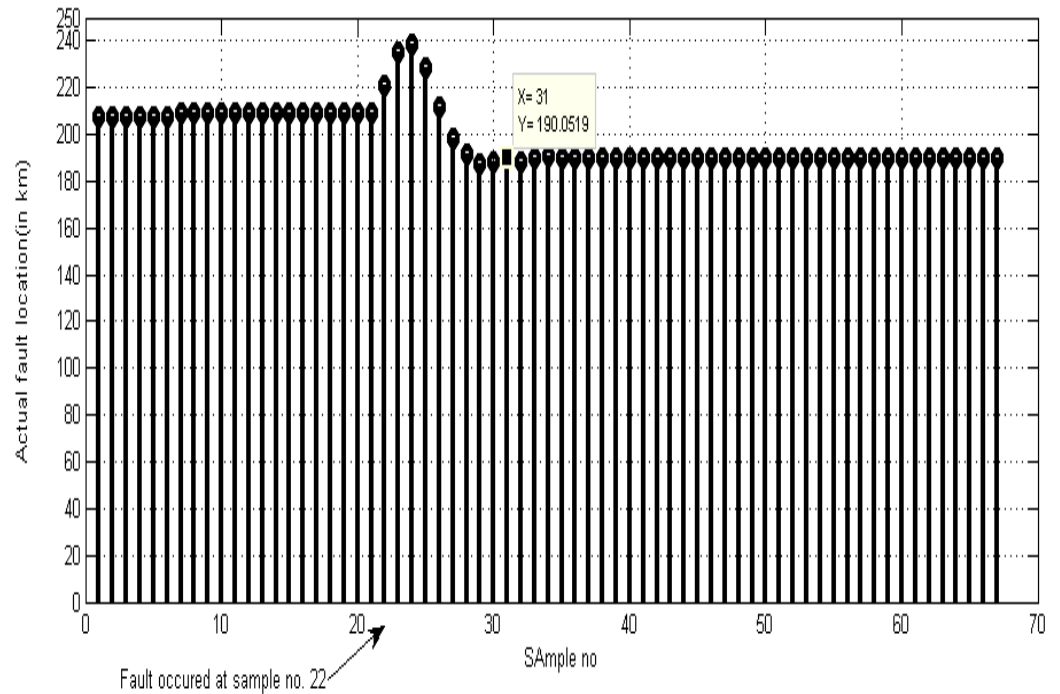

Figure 10(a). Test result of FL-1 during AG fault at $190 \mathrm{~km}$ from sending end with $100 \Omega$ fault resistance and fault inception time $=0.066 \mathrm{~s}$.

In Figure 10(b), plot is obtained for output of FL-2 during AG fault at 190km from sending end (or $90 \mathrm{~km}$ from FL-2 relay location) with $100 \Omega$ fault resistance and fault inception time $=0.066 \mathrm{~s}$. The fault occurred at sample no. 22 and located at sample no. 31 as $89.34 \mathrm{~km}$.

Inception of fault occurred at sample no. $22=22$ (consecutive samples) $* 1$ (sampling time) $=66 \mathrm{~ms}$

Fault located at sample no. $31=31 * 3$ (consecutive samples) $* 1($ sampling time $)=93 \mathrm{~ms}$

Also time of operation $=93-66 \mathrm{~ms}=27 \mathrm{~ms}$ (more than one full cycle)

Time of operation in terms of cycles $=27 \mathrm{msec} / 20 \mathrm{~ms}=1.35$ cycle time 


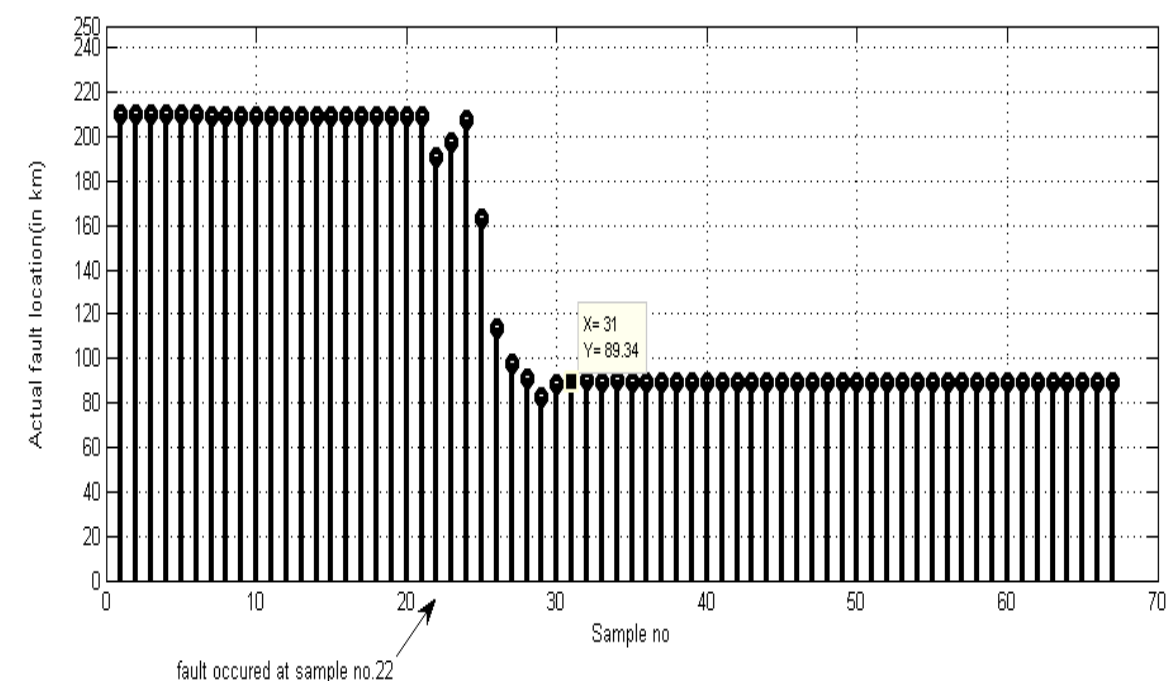

Figure 10(b). Test result of FL-2 during AG fault at 190km from sending end with $100 \Omega$ fault resistance and fault inception time $=0.066 \mathrm{~s}$.

Whenever a fault occurs in Section-1 for FL-1 detects it as forward fault and hence the distance from sending end is given as the output (i.e 0-100 kms). But the network FL-2 detects it as reverse fault and hence gives the distance as a negative value (i.e. -100 to 0). Again when there is a fault in Section-2, the network FL-1 gives its distance from the sending end (i.e. 0-200 kms) but the network FL-2 gives the distance from its position so its value lies between 0-100 kms.

\section{Percentage Errors in Distance Location Estimation}

At various locations different phase to ground faults were tested to find out the maximum deviation of the estimated distance $\mathrm{L}_{\mathrm{f}}$ measured from the relay location, from the actual fault location $\mathrm{L}_{\mathrm{a}}$. Then the resulted estimated error "e" is expressed as a percentage of total line length $\mathrm{L}$ of each section $(=100 \mathrm{~km})$ as

$e=\frac{L_{f}-L_{a}}{L} \times 100 \%$

The maximum percentage errors found in training, testing result and validation results are $(+2.98,-2.16),(+4.42,-4.92)$ and $(+5.39$,$5.14)$ respectively for FL-1 and $(+3.44,-2.75),(+2.7802,-2.063)$ and $(+3.54,-2.26)$ respectively for FL-2. Figure 11-12 shows the percentage error found in the testing data set of FL-1 and FL-2 respectively.

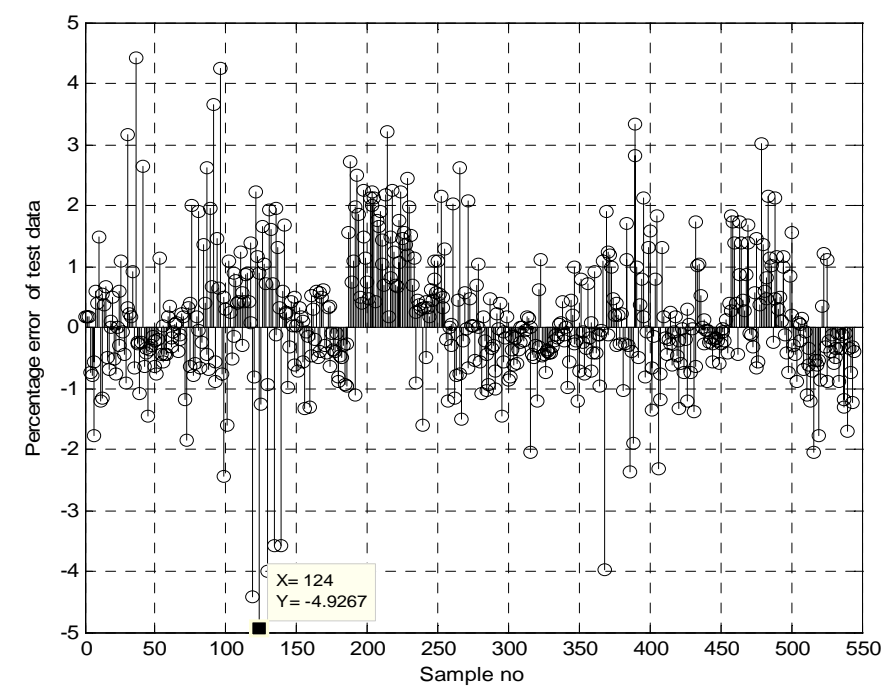

Figure 11. Percentage error in the output of testing data set for FL-1.

Table 4. Test result of FL-1 and FL-2 


\begin{tabular}{|c|c|c|c|c|c|}
\hline $\begin{array}{l}\text { Type } \\
\text { of } \\
\text { fault }\end{array}$ & $\begin{array}{l}\text { Distance from } \\
\text { sending end ( } L_{a} \\
\text { in kms) }\end{array}$ & $\begin{array}{l}\text { Distance estimated } \\
\text { by } F L-1\left(L_{\mathrm{f}} \text { in } \mathrm{kms}\right)\end{array}$ & $\begin{array}{l}\text { Error in } \\
\text { FL-1 (\%) }\end{array}$ & $\begin{array}{l}\text { Distance estimated } \\
\text { by FL-2 }\left(L_{\mathrm{f}} \text { in } \mathrm{kms}\right)\end{array}$ & $\begin{array}{l}\text { Error in } \\
\text { FL-2 (\%) }\end{array}$ \\
\hline $\mathrm{BG}$ & 25 & 26.0373 & 1.0373 & -76.5693 & 1.5693 \\
\hline CG & 170 & 169.5389 & 0.4611 & 70.9412 & 0.9412 \\
\hline AG & 35 & 35.8004 & 0.8004 & -65.6718 & 0.6718 \\
\hline $\mathrm{AG}$ & 185 & 184.4528 & 0.5472 & 85.3946 & 0.3946 \\
\hline $\mathrm{AG}$ & 165 & 164.2858 & 0.7142 & 64.8393 & 0.1607 \\
\hline $\mathrm{AG}$ & 190 & 190.0519 & 0.0519 & 89.34 & 0.66 \\
\hline
\end{tabular}

\section{Regression Analysis of FL-1 and FL-2}

The performance of a trained network can be measured to some extent by the errors on the training, validation and test sets, but it is often useful to investigate the network response in more detail. One option is to perform a regression analysis between the network response and the corresponding targets. The routine "postreg" of neural network toolbox of Matlab® 7.5 is used to perform this analysis. Here we pass the network output and the corresponding targets to postreg. It returns three parameters. The first two, $\mathrm{m}$ and $\mathrm{b}$, correspond to the slope and the $y$-intercept of the best linear regression relating targets to network outputs. If we had a perfect fit (outputs exactly equal to targets), the slope would be 1 , and the y-intercept would be 0 . The third variable returned by "postreg" is the correlation coefficient (R-value) between the outputs and targets. It is a measure of how well the variation in the output is explained by the targets. If this number is equal to 1 , then there is perfect correlation between targets and outputs.

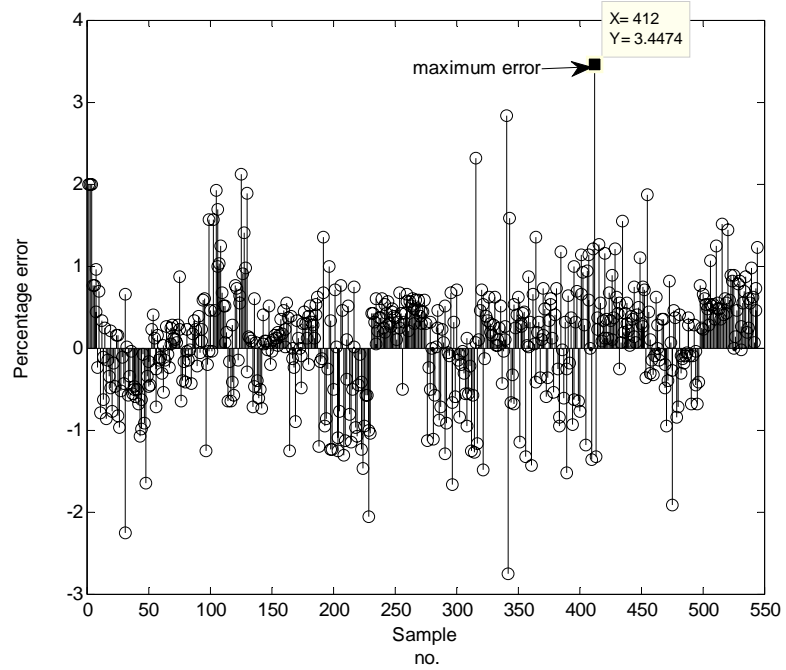

Figure 12. Percentage error in the output of testing data set for FL-2.

A linear regression analysis between the network outputs and the corresponding targets has been done for the entire data set obtained through the network training, validation and test and shown in the following Figure 13 (a) and (b). The network outputs are plotted versus the targets as open circles. The best linear fit is indicated by a dashed line. The perfect fit (output equal to targets) is indicated by the solid line. In the following Figures, it is difficult to distinguish the best linear fit line from the perfect fit line, because the fit is so good.

As we can see in Figure 13(a) shown below for regression analysis for FL-1, where Slope of regression plot $(\mathrm{m})=1$,

$\mathrm{Y}-$ Intercept $(\mathrm{b})=-0.057$ and Correlation coefficient $(\mathrm{R})=0.99937$;

Further Figure 13(b) shows the regression analysis for FL-2, where $m=1, R=0.99971$ and $b=-0.17$. Thus it's a good fit. 


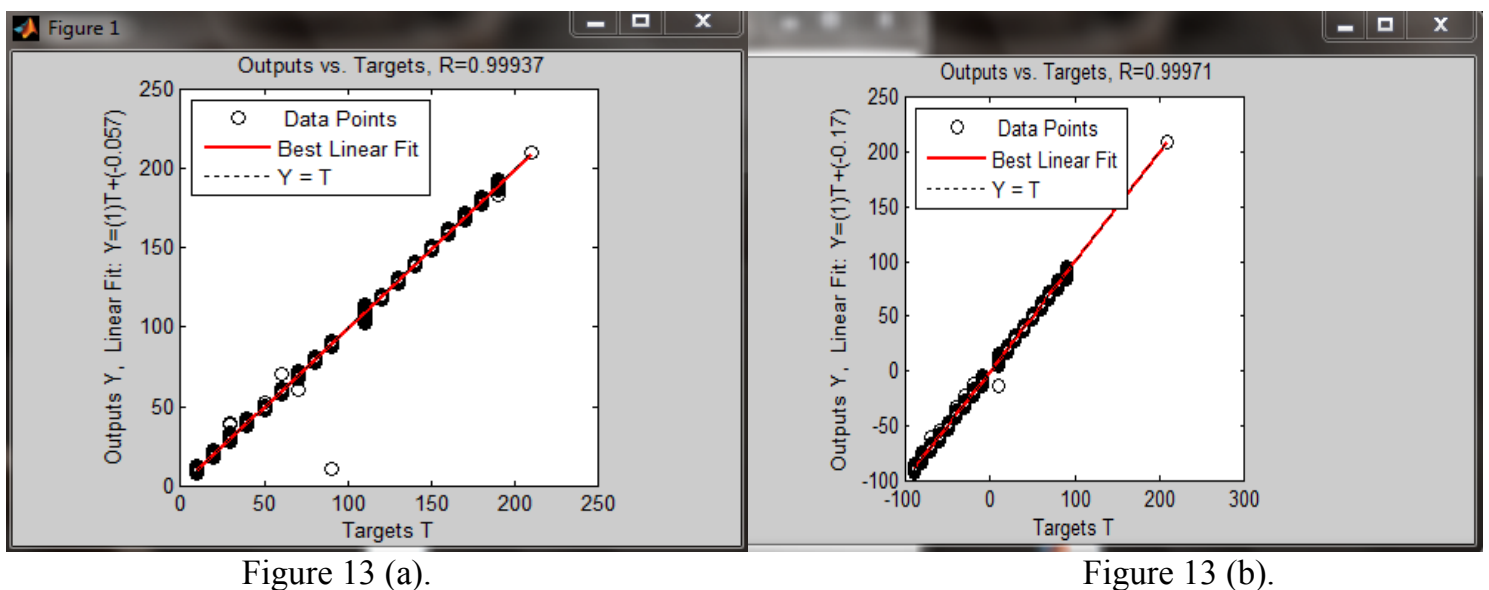

Figure 13 (a) and (b). Regression Analysis plot for training of FL-1 and FL-2 respectively.

\section{Conclusion}

An accurate algorithm for fault location estimation and direction detection of phase-to-ground faults on single circuit transmission line fed from sources at both ends is presented. The algorithm employs the fundamental components of three phase voltages and currents measured at one end only. The algorithm provides automatic determination of fault direction (forward or reverse) and fault location after one cycle from the inception of fault. The performance of the proposed scheme has been investigated by a number of offline tests. The complexity of the possible types of faults (AG, BG, and CG), fault locations ( 0 $90 \%$ ), fault inception angles $\left(0 \& 90^{\circ}\right)$, fault resistance $(0-100 \Omega)$ and remote end in-feed are solved. The proposed scheme has significant advantage over more traditional direction relaying algorithms viz. it is suitable for high resistance fault and is not affected by varying fault inception angle, remote end faults. It has the operating time of less than 1.5 cycles as it uses the one cycle DFT. The technique does not require communication link to retrieve the remote end data. The proposed scheme allows the protection engineers to increase the reach setting upto $90 \%$ of the line length i.e. greater portion of line length can be protected as compared to earlier techniques in which the reach setting is $85 \%$ only.

\section{References}

Coury, D. V. and Jorge, D.C., 1998. Artificial Neural Network Approach to Distance Protection of Transmission Lines. IEEE Trans. on Power Delivery, Vol.13, No.1, pp. 102-108.

Chunju, Fan, Li, K.K., Chan, W.L., Weiyong, Yu and Zhaoning, Zhang, 2007. Application of wavelet fuzzy neural network in locating single line to ground fault (SLG) in distribution lines. International Journal of Electrical Power \& Energy Systems, Vol.29, No.6, Pages 497-50.

Crossley, P.A., Elson, S.F., Rose, S.J., and Williams, A., 1989. The design of a superimposed component directional comparison protection. Int. Conf. Developments in Power System Protection, IEE Conf. Publ., Vol. 302, pp. 151-155

Gao, H., Crossley, P.A., 2006. Design and evaluation of a directional algorithm for transmission-line protection based on positivesequence fault components. IEE Proc.-Gener, Transm. Distrib. Vol.153, No.6.

He, J.L, Zhang, Y.H., and Yang, N.C., 1984. New type power line carrier relaying system with directional comparison for EHV transmission lines. IEEE Trans. Power Appar. Syst., Vol. 103, No.2, pp. 429-436.

Johns, A.T., 1980. New ultra-high-speed directional comparison technique for the protection of EHV transmission lines. IEE Proc. C, Gener. Power Trasns. Distrib., Vol. 127, pp. 228-239.

Johns, A.T., Barker, A., Martin, M.A., Walker, E.P., and Crossley, P.A., 1986. A new approach to EHV directional comparison protection using a digital signal processor. IEEE Trans. Power Deliv., Vol.1, No.2, pp. 24-34.

Jain, Anamika, Kale, V.S. and Thoke, A.S., 2006. Application of artificial neural networks to transmission line faulty phase selection and fault distance location. Proceedings of the IASTED International conference "Energy and Power System", Chiang Mai, Thailand, paper No. 526-803, Pages 262-267.

Khaparde, S.A., Warke, N. and Agarwal, S.H., 1996. An adaptive approach in distance protection using an artificial neural network. Electric Power Systems Research, Vol.37, No.1, Pages 39-46.

Kezunoic, M., 1997. A Survey of Neural Net Application to Protective Relaying and Fault Analysis. Eng. Int. Sys., Vol. 5, No.4, pp. 185-192.

Lyonette, D.R.M., Bo, Z.Q., Weller, G., and Jiang, F., 2000. A new directional relay for the protection of EHV transmission lines based on the detection of transient voltage signals. IEEE PES Winter Meeting, pp. 1827-1831. 
Mazon, A.J., Zamora, I., Minambres, J. F., Zorrozua, M.A., Barandiaran, J.J. and Sagastabeitia, K., 2000. A new approach to fault location in two-terminal transmission lines using artificial neural networks. Electric Power Systems Research Journal, Vol. 56, pp-261-266.

Oonsivilai, A. and Saichoomdee, S., 2009. Distance transmission line protection based on radial basis function neural network. World Academy of Science, Engineering and Technology, Vol. 60.

Ravikumar B., Thukaram D. and Kincha H.P., 2008. Application of support vector machines for fault diagnosis in power transmission system, IET Gener. Transm. Distrib., vol.2, no.1, pp.119-130.

Reddy M.J. and Mohanta D. K., 2006. A comparative study of artificial neural network (ANN) and fuzzy information system (FIS) approach for digital relaying of transmission line faults, AIML journal, vol.6, no.4, pp. 1-7.

Reddy M.J. and Mohanta D.K., 2007. A wavelet-fuzzy combined approach for classification and location of transmission line faults, Electrical Power and Energy Systems, vol.29, no.1, pp.669-678.

Salat R. and Osowski S., 2004. Accurate fault location in the power transmission line using support vector machine approach, IEEE Trans. Power Delivery, vol.19, No.2., pp.979-986.

Samantaray S.R. and Dash P.K., 2008. Transmission line distance relaying using machine intelligence technique, IET Gener. Transm. Distrib., vol.2, no.1, pp.53-61.

Samantaray S.R., Dash P.K. and Panda G., 2007. Distance relaying for transmission line using support vector machine and radial basis function neural network, Electrical power and energy systems, vol. 29, no.7, pp.551-556.

Samantaray S.R., 2009. Decision tree-based fault zone identification and fault classification in flexible AC transmission-based transmission line, IET Gener. Transm. Distrib, vol. 3, Iss.5, pp. 425-436.

Sanaye-Pasand M. and Kharashadi-Zadeh H.,2006. An extended ANN-based high speed accurate distance protection algorithm, Electrical Power and Energy Systems, vol.28, no.6, pp. 387-395.

Sidhu, T.S., Singh, H., Sachdev, M.S., 1995. Design, implementation and testing of an artificial neural network based fault direction discriminator for protecting transmission lines. IEEE Transaction on Power Delivery, Vol. 10, No.2.

Tamer S. Kamel , M.A. Moustafa Hassan., 2010. Adaptive Neuro fuzzy interface system for classification in the transmission lines. OJEEE, Vol. 2, No.1.

Venkataramana Kola Babu, Tripathy Manoj and Singh Asheesh K., 2011. Recent techniques used in transmission line protection: a review. International Journal of Engineering, Science and Technology, Vol. 3, No. 3, pp. 1-8.

Warlyani Prarthana, Jain Anamika Thoke A.S. and Patel R. N., 2011 "Fault classification and faulty section identification in teed transmission circuits using ANN", International Journal of Computer and Electrical Engineering, Vol.3, No.6, pp. 807-811.

Xia, Y.Q., He, J.L., and Li, K.K., 1992. A reliable directional relay based on compensated voltage comparison for EHV transmission lines. IEEE Trans. Power Deliv., Vol. 7, No.4, pp. 1955-1962.

\section{Biographical notes}

Anamika Yadav received her B.E. in Electrical Engineering from RGPV Bhopal in year 2002. She acquired her M.Tech in Integrated Power Systems from V.N.I.T., Nagpur, India in 2006. She worked as Assistant Engineer in the Chhattisgarh State Electricity Board, Raipur, C.G, India from July, 2004 to March, 2009. Since March 2009 she is working as Assistant Professor in department of Electrical Engineering, National Institute of Technology, Raipur, C.G., India. Her research interest is in application of ANN to Power System protection. Dr. Yadav is a member of The IET, with designatory title M.I.E.T., member of IEEE and Associate member of I.E. India. She has published more than 25 papers in referred international, national journals and conferences.

Dr. A.S. Thoke did his B.E., M. Tech. and PhD. all in Electrical Engineering. He is a Professor in Electrical Engineering at National Institute of Technology, Raipur (C.G.), India. Dr. Thoke has a teaching \& research experience of 38 years. His fields of interest are application of Artificial Intelligence to Power system with particular interest in protection. Dr. Thoke is Member of IEEE and IEEE Power engineering society and I.E. India. He has published more than fifty papers in referred international, national journals and conferences.

Received December 2011

Accepted February 2012

Final acceptance in revised form March 2012 